\title{
Micro-encapsulation of ozonated red pepper seed oil with antimicrobial activity and application to nonwoven fabric
}

\author{
F. Özyıldız ${ }^{1 \dagger}$, S. Karagönlü${ }^{2}$, G. Basal ${ }^{2}$, A. Uzel ${ }^{1}$ and O. Bayraktar ${ }^{3}$ \\ 1 Department of Biology, Ege University, Bornova-Izmir, Turkey \\ 2 Department of Textile Engineering, Ege University, Bornova-Izmir, Turkey \\ 3 Department of Chemical Engineering, Izmir Institute of Technology, Urla-Izmir, Turkey
}

Significance and Impact of the Study: This is the first report on the antimicrobial action of RPSO after ozonation process. These findings suggest that ozonated red pepper seed oil (ORPSO) may be a useful and effective antimicrobial agent against the micro-organisms with antibiotic resistance. Therefore, as a natural product, RPSO represents a sustainable alternative to the use of synthetic antimicrobial agents. To our knowledge, this is also the first time that ORPSO has been micro-encapsulated for the preparation of functional textile material with significant antimicrobial activity.

\section{Keywords}

antimicrobial activity, complex coacervation, functional fabrics, gelatin, gum arabic, microencapsulation, ozonation, red pepper seed oil.

\section{Correspondence}

Figen Özyıldız, Department of Biology, Ege University, Bornova, 35100, Izmir, Turkey.

E-mail: figenozyildiz@gmail.com

†Present address: Vali Vecdi Gönül High School, Hatay-Izmir, Turkey.

2012/0973: received 23 July 2012, revised 19 November 2012 and accepted 19 November 2012

doi:10.1111/lam.12028

\begin{abstract}
In recent years, functional fabrics possessing antimicrobial activity have drawn significant interest because antibiotic resistance is becoming widespread among pathogenic micro-organisms. The aim of this study was to produce microcapsules incorporating ozonated red pepper seed oil (ORPSO) with antimicrobial properties and apply them to nonwoven fabrics to prepare functional textiles. Red pepper seed oil (RPSO) was ozonated and microencapsulated via a complex coacervation method using gelatin (GE) and gum arabic (GA) as wall materials. While micro-encapsulation yield and oil loading decreased with increases in the amount of surfactant, the mean particle size increased. The antimicrobial activity of the oil was tested via the disc diffusion method. The microcapsules were also tested using the agar well method. While RPSO had no effect on the test micro-organisms, the ORPSO and microcapsules containing ORPSO were found to be active against the test micro-organisms. The microcapsules were then applied to nonwoven fabric using the padding method to produce a disposable functional textile. The microcapsule-impregnated functional fabrics provided a $5 \log$ decrease in $1 \mathrm{~h}$. It is therefore possible to functionalize nonwoven fabrics to have antimicrobial activity against antibiotic-resistant micro-organisms, using microcapsules containing ORPSO.
\end{abstract}

\section{Introduction}

Recently, antimicrobial textiles have been widely used in home textiles and personal care products. Currently, disposable nonwoven textiles with antimicrobial properties are widely used in the production of functional textiles. There are various methods to extend the antimicrobial properties of textiles. One of these is the use of micro-encapsulated antimicrobial agents within the fibre matrix (Ramachandran et al. 2004; Bonin 2008; Tavaria et al. 2012).
Micro-encapsulation is a technique of surrounding solid particles, liquid droplets or gas bubbles with a continuous film or polymeric material. Microcapsules range in size from $1 \mu \mathrm{m}$ to $1 \mathrm{~mm}$ (Benita 1996; Mayya et al. 2003). A variety of techniques have been developed for micro-encapsulation. Coacervation, based on the phase separation of one or many hydrocolloids, is one technique. Coacervation is divided into simple and complex coacervation. While simple coacervation involves the use of a single polymer in organic or aqueous media, complex 
coacervation involves the use of two oppositely charged polymeric materials (Benita 1996; Aguilera and GómezGonzález 2008; Leclercq et al. 2009). Complex coacervation, firstly used in carbonless copying paper by Green et al. (1957), is the oldest and most commonly preferred micro-encapsulation method. It is also simple and technically easy. The complex coacervation technique involves five steps to obtain microcapsules: dissolution of the polymer, emulsification, coacervation, hardening and rinsing/ filtering/drying (Cosco et al. 2007; Harrington and Morris 2009; Bansode et al. 2010).

Proteins and polysaccharides, particularly gelatin (GE) (type A) and gum arabic (GA), are generally used for complex coacervation because of their natural, environmental- friendly and biodegradable properties (Leclercq 2008). A variety of materials have been packaged by micro-encapsulation. GE/GA-based microcapsules have been studied using several core materials such as vetiver oil (Prata et al. 2008), shikonin (Huang et al. 2007), camphor oil (Chang et al. 2006), violet, lemon and peach perfumes (Ovez and Yuksel 2002), orange oil (Vahapzadeh et al. 2004), paraffin oil (Mayya et al. 2003; Onder et al. 2008), N-benzylmorpholine (Bukar et al. 2008), indomethacin (Daniels and Mittermaier 1995), limonene and menthol powder (Leclercq et al. 2009), capsaicin (Xing et al. 2004) and flavor oil (Yeo et al. 2005).

Micro-encapsulation technology has been used in numerous fields including textiles, agriculture, pharmaceuticals, food and cosmetics for multiple purposes (Nelson 2002; Augustin and Hemar 2009). In the textile industry, many different core materials such as fragrances (Hong and Park 1999; Rodrigues et al. 2009), fire retardants (Giraud et al. 2005), insect repellents (N'Guessan et al. 2008), dyes (El-Zawahry et al. 2007; Leelajariyakul et al. 2008), phase change materials (Qingwen et al. 2007; Deveci and Basal 2009) and drugs (Ma et al. 2009) have been successfully encapsulated. Microcapsules can be applied to textile materials by padding, spraying, coating and exhaust techniques (Badulescu et al. 2008). There is also a rising interest in using plant and vegetable products such as extracts and oils in the medical industry. Some plant-originated products with anti-oxidant and antimicrobial activities represent an important segment of the literature (Hammer et al. 1999). Capsicum annuum L. has been widely used as red pepper powder. Amongst the pepper-producing countries, Turkey ranks third after China and Mexico (Frratligil-Durmuş and Evranuz 2010). Red pepper seeds can be considered as byproducts of red pepper powder production. Red pepper seeds contain protein, oil and fibre along with several amino acids (El-Adawy and Taha 2001a; Firatligil-Durmuş and Evranuz 2010). Currently, red pepper seeds are a subject of research, and it has been found that the red pepper seed is rich in anti-oxidants (Sim and Sil 2008; Song et al. 2010). Recently, more attention has been focused on the characterization and utilization of red pepper seed oil (RPSO) (El-Adawy and Taha 2001a; Li et al. 2011).

Ozone treatment of vegetable oils is also being investigated for medical applications. Upon ozone treatment, ozone gas dissolves in vegetable oils and forms ozonides (Cronheim 1947; FAO 2008; Zanardi et al. 2008). Ozonides are generally believed to be responsible for the broad biological activities of ozonated vegetable oils. Ozonated oils are used in the medical and pharmaceutical industries and in general health care (Holmes 2008). To the best of our knowledge, no report concerning the use of micro-encapsulated ozonated red pepper seed oil (ORPSO) and its application to nonwoven fabric to produce a disposable antimicrobial textile material has been published in the literature.

In this study, ORPSO with antimicrobial activity was micro-encapsulated using GE and GA as wall material by complex coacervation. Optimum processing parameters, including amounts of RPSO and surfactant, were studied and their effects on yield, particle size, microcapsule loading and release were investigated. Microcapsules obtained under optimum conditions were then applied to nonwoven fabric using the padding method to produce a disposable medical textile with antimicrobial properties.

\section{Results and discussion}

\section{Characterization of RPSO and ORPSO}

Red pepper seed has been found to be rich in its oil $(24 \cdot 4 \%)$ and protein $(25 \cdot 91 \%)$ content (Frratligil-Durmuş and Evranuz 2010). RPSO is also reported to be rich in unsaturated fatty acids; linoleic acid (74\%) and oleic acid (13\%) which are reported to be major acids in RPSO (Jung et al. 1999; El-Adawy and Taha 2001a,b; Duarte et al. 2004; Li et al. 2011). In this study, the oil yield was found to be $21 \%$ under the defined conditions and this value matched well with the previously reported yield values. The major saturated fatty acids in oil were reported to be palmitic and stearic acids. The total saturated fatty acid content of seed oil is reported to be $17 \cdot 6 \%$ in the literature (El-Adawy and Taha 2001a; Firatlıgil-Durmuş and Evranuz 2010; Li et al. 2011).

In RPSO, the most abundant unsaturated free fatty acids (UFFA) were reported to be linolenic acid and oleic acid. The fatty acid content and degree of unsaturation of RPSO show similarities to those of sunflower and safflower oils, which have linoleic acid as the most abundant fatty acid, followed by oleic acid. This reveals a high degree of unsaturation in RPSO. 
Ozone treatment of vegetable oils (Maritza et al. 2006) is also a new field for medical, pharmaceutical and dermocosmetic applications due to its antimicrobial activity. It has been shown that ozone treatment of unsaturated fatty acids can cause the conversion of olefinic bonds to ozonides (Harrison and Murphy 1996). The chemical reactions occurring during ozone treatment of oil are very complex. These reactions cause changes in functional groups during ozonation, which can be explained by the well-known Criegee mechanism such as the formation of ozonides from alkenes and ozone (Soriano et al. 2003a,b). In this study, the effects of ozonation on the chemical composition of RPSO were analyzed using Gas chromatography-mass spectrometry (GC-MS) and FT-IR analyses.

\section{Gas chromatography-mass spectrometry analysis}

The ozonated RPSO sample was subjected to GC coupled with a mass spectrometer to determine its constituents. A literature search was performed to compare the selected mass spectra with the spectra of reference compounds. Using the GC/MS spectral results, the aldehydes 1-nonanal (nonaaldehyde or pelargon aldehyde, $14.88 \%$ in abundance), 2-nonenal ( $0 \cdot 33 \%$ in abundance), 4-nonenal (31.96\% in abundance), and 1-hexanal (hexanaldehyde, $10.93 \%$ in abundance) were identified as the major volatile components. Carboxylic acids such as nonanoic acid (pelargonic acid, $7 \cdot 23 \%$ in abundance), hexanoic acid (11.32\% in abundance) and 8 -nonenoic acid $(6.47 \%$ in abundance) were also detected in our ORPSO samples.

\section{FTIR spectroscopy}

In the analysis of RPSO and ORPSO with IR spectroscopy, wavelengths corresponding to primary aldehydes and carboxylic acids were evaluated. The spectra were checked for double bonds, $\mathrm{C}=\mathrm{C}$ stretching $\left(1654 \mathrm{~cm}^{-1}\right)$ and $=\mathrm{C}-\mathrm{H}$ stretching $\left(3009 \mathrm{~cm}^{-1}\right)$ (Vlachos et al. 2006), as well as ozonide CO stretching $\left(1105 \mathrm{~cm}^{-1}\right)$ by unsaturated fatty acid moieties (Soriano et al. 2003a,b; John et al. 2004). As seen in Fig. 1, RPSO samples showed strong absorbance at approximately 1700, 2900 and $3500 \mathrm{~cm}^{-1}$ infrared (IR). The presence of free fatty acids in RPSO can be identified from its FT-IR spectrum.

The presence of linoleic acid in RPSO samples was revealed from these results. In the FTIR spectrum of ORPSO, absorptions are sharp and strong around $1750 \mathrm{~cm}^{-1}$ due to the carbonyl group. In addition, after ozonation, a peak was observed due to $\mathrm{OH}$ that revealed the presence of aldehydes and carboxylic acids. The $\mathrm{C}=\mathrm{O}$ bond specific to carboxylic acid was observed at $1100 \mathrm{~cm}^{-1}$. The increase in the intensity of this band demonstrates the formation of carboxylic acids after ozone treatment. Nonanoic acid detected by GS/MS analysis could also be identified in the FT-IR spectra as a carboxylic acid.

It is a known phenomenon that the ozonide and peroxide oligomers formed are unstable and eventually decompose to a mixture of aldehydes and carboxylic acids. The most important industrial use of ozone treatment is the cleavage of oleic acid to nonanoic acid (pelargonic acid) and di-nonanoic acid (azelaic acid) (Baumann et al. 1988).

Decomposition of triolein ozonide leads to the formation of aldehydes and acids (pelargonic acid, azelaic acid, caproic acid). Similar ozone treatment products of linoleic acid and oleic acids have also been reported in the literature (Cronheim 1947). It is known that dicarboxylic acids can be produced industrially by ozonolysis of oleic acid to azelaic acid (Hill 2007; Köekritz and Martin 2011).

RPSO primarily contains large amounts of linoleic acid followed by oleic acid. Saturated fatty acids such as palmitic and stearic acids do not react with ozone but remain intact (Tran et al. 2005). The ozonation reaction in RPSO occurs mainly through linoleic acid and oleic acid.

Aldehydes are the major volatile reaction products after ozonation of RPSO; 1-nonanal was detected following reaction with oleic acid; 2-nonenal, 4-nonenal and 1-hexanal were detected following reaction with linoleic acid. Azelaic acid was identified as a liquid-phase reaction product following reaction with oleic acid (Moise and Rudich 2002).

Nonanal, also known as nonanaldehyde or pelargonaldehyde, is an alkyl aldehyde detected in ORPSO. It has a

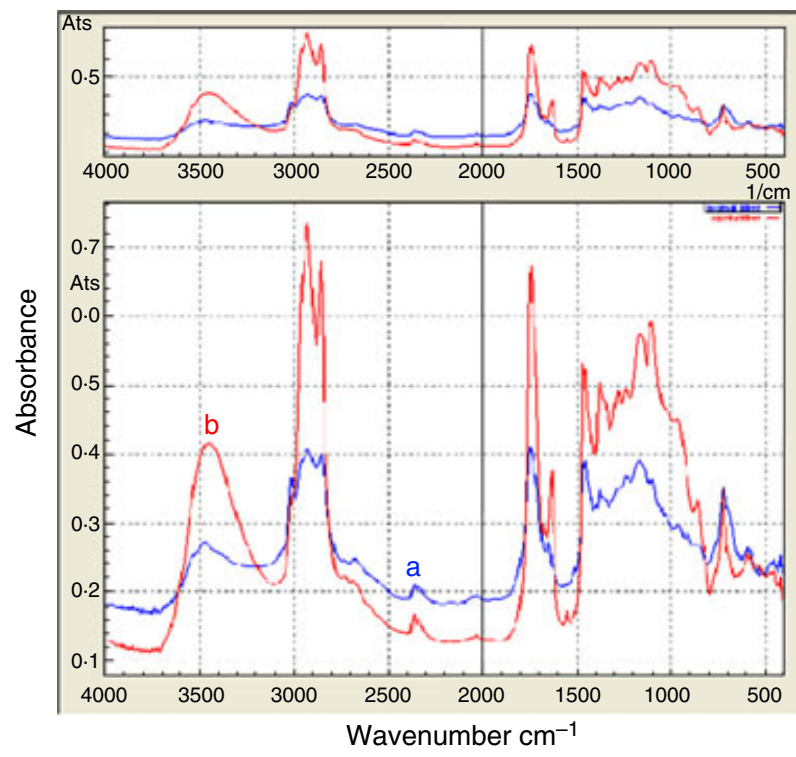

Figure 1 FT-IR spectra of: (a) red pepper seed oil, and (b) ozonated red pepper seed oil. 
strong fruity or floral odour and is used as a fragrance in industry. Hexanal (hexanaldehyde), found in ORPSO, is an alkyl aldehyde used in the flavour industry to produce fruity flavours. Its scent is similar to that of freshly cut grass.

\section{Formation of microcapsules}

In this study, ORPSO microcapsules with antimicrobial activity were developed and successfully applied to nonwoven fabrics for medical use. The aim of developing bioactive textiles is to prevent infections in the case of injury, promote healing and improve health. Therefore, antibiotic-resistant test strains were used for a more realistic simulation of the implementation of the bio-active fabrics.

ORPSO was obtained and encapsulated successfully via a complex coacervation method using GE and GA as wall material. The antimicrobial activity of both the oil and the microcapsules was tested. The shape and formation of the microcapsules were observed under an optical microscope. It can be seen in the microscopic images that the microcapsules have a spherical shape and a smooth wall. In Fig. 2, particles surrounded by a black line are microcapsules. It is apparent that the microcapsules have a spherical shape. While the black lines are the walls of the microcapsules, the materials surrounded by a black line are their cores. The microcapsules have a single and continuous core. Their mean particle size increased with an increase in both, the amount of surfactant and oil.
To optimize the parameters for micro-encapsulation of ORPSO, an experimental design was set up. The effects of varying the processing parameters, including the amount of oil and amount of surfactant, on encapsulation yield, mean particle size, oil loading and oil release were investigated.

\section{Micro-encapsulation yield}

The statistical effects of the two parameters, amount of oil and amount of surfactant, on micro-encapsulation yield were calculated together and separately using SPSS statistical analysis software (SPSS Inc., Chicago, IL, USA). As a result of the statistical analysis, it was determined that these parameters, either together or separately, had no statistically significant effect on the micro-encapsulation yield.

Mean micro-encapsulation values obtained from all experiments are displayed in Table 1. Although the statistical analysis showed that the amount of surfactant did not have any effect on the micro-encapsulation yield, it can be seen in Table 1 that the micro-encapsulation yield decreased with increasing amounts of surfactant.

\section{Particle size and particle-size distribution}

The effects of the two parameters on particle size were also analyzed, both together and separately, using SPSS. As a result, while the amount of oil had no effect on size,

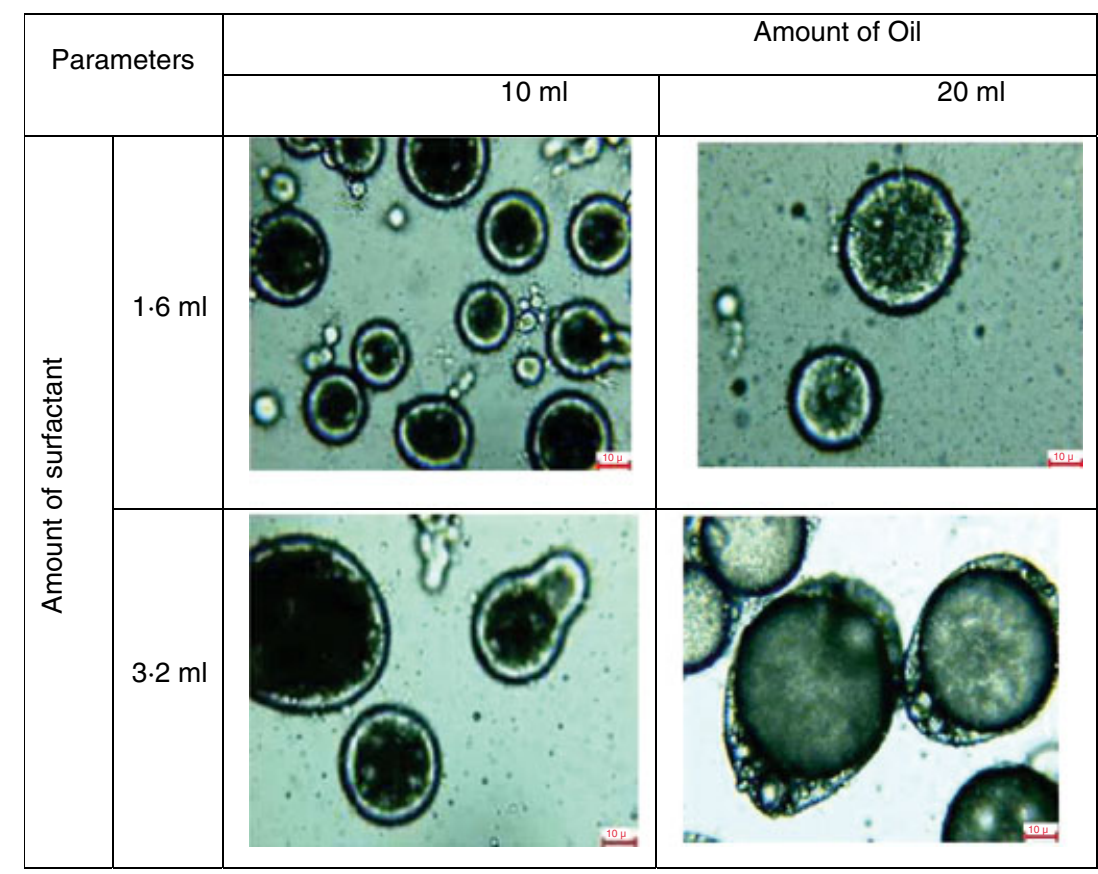

Figure 2 Optical microscope images of microcapsules. 
Table 1 Values of micro-encapsulation yield, mean particle size, oil loading and oil release

\begin{tabular}{|c|c|c|c|c|c|c|}
\hline $\begin{array}{l}\text { Experiment } \\
\text { number }\end{array}$ & $\begin{array}{l}\text { Amount } \\
\text { of oil (ml) }\end{array}$ & $\begin{array}{l}\text { Amount of } \\
\text { surfactant }(\mathrm{ml})\end{array}$ & $\begin{array}{l}\text { Micro-encapsulation } \\
\text { yield (\%) }\end{array}$ & $\begin{array}{l}\text { Particle } \\
\text { size (micron) }\end{array}$ & Oil loading (\%) & Oil release (\%) \\
\hline 1 & 10 & 1.6 & $87 \cdot 3$ & $18 \cdot 7$ & $53 \cdot 0$ & $42 \cdot 8$ \\
\hline 2 & 10 & $3 \cdot 2$ & $68 \cdot 8$ & $35 \cdot 5$ & $47 \cdot 5$ & $47 \cdot 0$ \\
\hline 3 & 20 & 1.6 & $76 \cdot 9$ & $27 \cdot 3$ & $56 \cdot 1$ & $49 \cdot 0$ \\
\hline 4 & 20 & 3.2 & 75.2 & 38.7 & 54.6 & $42 \cdot 3$ \\
\hline
\end{tabular}

the two parameters together had a significant effect. But as seen in Table 1, when the amount of oil or amount of surfactant increases, the particle size increases as well. The effect of changing the amount of oil in the mixture on the particle size is an expected result. A previous article, by Xing et al. (2004), does not support this result. It can be attributed to compositional changes due to oxidation of free fatty acids in RPSO with ozone treatment.

\section{Oil loading/release}

The mean values of oil loading and release are given in Table 1. As a result of the statistical analysis, it was concluded that amount of surfactant and oil, either together or separately had no statistically significant effect both on oil loading percentage and oil release. As seen from the results, the use of $10 \mathrm{ml}$ of oil and $1.6 \mathrm{ml}$ of surfactant resulted in a maximum microencapsulation yield for the preparation of microcapsules with ORPSO. At these conditions, the micro-encapsulation yield, mean size of microcapsules, oil loading and oil release were determined to be $87.3 \%, 18.7 \mu, 53$ and $42 \cdot 8 \%$ respectively.

\section{Impregnated microcapsules in padded fabric}

In Fig. 3, dry fabrics with and without microcapsules are shown. The materials with spherical shapes are microcap-

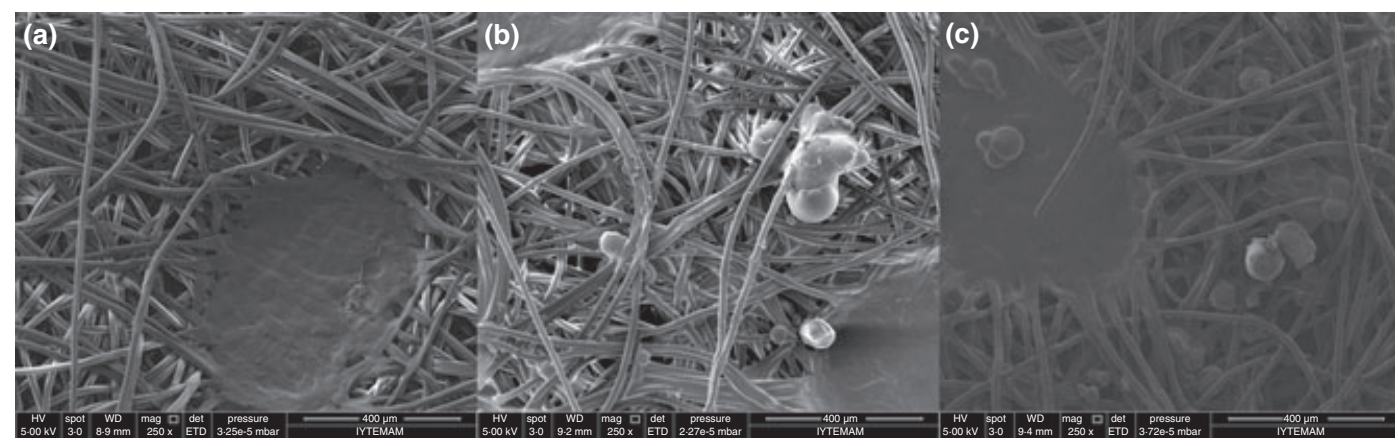

Figure 3 SEM images of fabrics with and without microcapsules: (a) fabric without microcapsules, (b) fabric passed through bath including $20 \mathrm{~g} \mathrm{I}^{-1}$ microcapsules, (c) fabric passed through bath including $30 \mathrm{~g} \mathrm{I}^{-1}$ microcapsules.

Table 2 The results of antimicrobial disc diffusion tests for red pepper seed oil (RPSO) and ozonated red pepper seed oil (ORPSO)

\begin{tabular}{|c|c|c|c|c|c|c|c|c|c|c|c|}
\hline \multirow[b]{3}{*}{ Micro-organisms } & \multicolumn{11}{|c|}{ Inhibition zone $(\mathrm{mm})^{*}$} \\
\hline & \multicolumn{3}{|c|}{$\% 10$ DMSO } & \multicolumn{3}{|c|}{$\% 25$ DMSO } & \multicolumn{3}{|c|}{$\% 50$ DMSO } & \multicolumn{2}{|l|}{ Antibiotics } \\
\hline & $\mathrm{C}$ & RPSO & ORPSO & C & RPSO & ORPSO & $\mathrm{C}$ & RPSO & ORPSO & $\begin{array}{l}\mathrm{G}(10 \mu \mathrm{g} \\
\text { per disc) }\end{array}$ & $\begin{array}{l}\mathrm{N}(100 \mathrm{U} \\
\text { per disc) }\end{array}$ \\
\hline Escherichia coli $\mathrm{O} 157 \mathrm{H} 7$ & 0 & 0 & 13 & 0 & 0 & 13.5 & 0 & 0 & 15 & 21 & $\mathrm{Nt}$ \\
\hline Pseudomonas aeruginosa ATCC 27853 & 0 & 0 & 12 & 0 & 0 & 11 & 0 & 0 & 14 & 25 & $\mathrm{Nt}$ \\
\hline Methicillin-resistant Staphylococcus aureus & 0 & 0 & 23 & 0 & 0 & 23 & 0 & 0 & 20 & 23 & $\mathrm{Nt}$ \\
\hline Vancomycin-resistant Enterococcus faecium & 0 & 0 & 27 & 0 & 0 & 23 & 0 & 0 & 15 & 19 & $\mathrm{Nt}$ \\
\hline Candida albicans & 0 & 0 & 16 & 0 & 0 & 15 & 0 & 0 & 15 & $\mathrm{Nt}$ & 18 \\
\hline
\end{tabular}

Nt, not tested; C, DMSO controls corresponding to $10 \%, 25 \%$, and $50 \%$ (v/v) concentrations; G, Gentamycin; N, Nystatin.

*The values are the mean of three experiments. Zones of inhibition include the diameter of the disc. 
sules. It can also be observed that the microcapsules have a smooth surface.

The difference between dry fabrics passed through baths containing 20 or $30 \mathrm{~g} \mathrm{l}^{-1}$ of microcapsules is shown in Fig. 4. It is clear from the figure that more microcapsules were impregnated in the fabric applied to the $30 \mathrm{~g}^{-1}$ microcapsule bath.

\section{Antimicrobial activities of RPSO, ORPSO, microcapsules} and fabrics

The antimicrobial activities of RPSO and ORPSO were found to be quite different. The antimicrobial activities of the RPSO and ORPSO are shown in Table 2. Different concentrations of DMSO and RPSO showed no antagonistic activity against the test strains, but ORPSO samples showed considerable activity compared with those of antibiotics. This effect can be attributed to the ozone treatment. In a previous study, Agaoglu et al. (2007) similarly found that crushed red pepper was ineffective against a panel of test micro-organisms including Staphylococcus aureus, Escherichia coli and Candida albicans. In another research, capsaicin, the major metabolite of red pepper, was also not found to be very active against E. coli and Saccharomyces cerevisiae (Torres et al. 1999). However, in another study, the authors reported that a combination of C. annuum extract and sodium chloride had an inhibitory effect against Salmonella typhimurium and Pseudomonas aeruginosa in meat samples (Careaga et al. 2003). In our study, the antimicrobial effect of ORPSO can be explained by the presence of antimicrobial compounds such as aldehydes and carboxylic acids (e.g. azelaic and pelargonic acids) formed by the ozonation process. Azelaic acid inhibits the growth of skin bacteria that cause acne, and keeps skin pores clear. Its antimicrobial activity is attributed to the inhibition of microbial cellular protein synthesis (Leeming et al. 1986; Porro 1987). Nonanoic acid is used in the food industry, particularly for its antifungal properties (Mirabal et al. 2003; Sahin et al. 2006).

The results in Table 3 show that the encapsulated ozone treated with oil retained its antimicrobial activity in the microcapsule form. This prolonged activity is important for the production of functional textiles.

Microcapsules produced under optimum conditions were impregnated into the nonwoven fabric using two different baths with either 20 or $30 \mathrm{~g} \mathrm{l}^{-1}$ of microcapsules and the antimicrobial activities of the fabrics were tested. The bath containing $20 \mathrm{~g} \mathrm{l}^{-1}$ of microcapsule was sufficient to confer antimicrobial activity to the fabric. The efficacy of the bioactive fabrics is shown in Table 4. Microcapsule-impregnated fabrics are clearly more effective than the untreated fabrics $(P<0 \cdot 05)$.

Although a statistically significant decrease was found between initial microbial counts (IMC) and final microbial counts (FMC) $(P<0.05)$ in the control fabrics, they still had biologically significant $\left(10^{4}-10^{5} \mathrm{CFU} \mathrm{ml} \mathrm{m}^{-1}\right)$ microbial counts. However, biologically active fabrics eliminated the test micro-organisms, showing up to 5-log decrease in $1 \mathrm{~h}$. Both bio-active fabrics impregnated with $20 \%(\mathrm{w} / \mathrm{w})$ bio-active microcapsules (BAF1) and bioactive fabrics impregnated with $30 \%(\mathrm{w} / \mathrm{w})$ bio-active microcapsules (BAF2) were found to be very active against the antibiotic-resistant test micro-organisms. Compared to other bioactive fabrics containing silver ions (Mariscal et al. 2010), ozone-treated oil-containing microcapsules provided more effective and rapid protection against bacteria.

In this article, the preparation of ORPSO containing microcapsules by complex coacervation and their application to nonwoven fabrics to prepare functional textiles has been tested. While RPSO does not possess significant

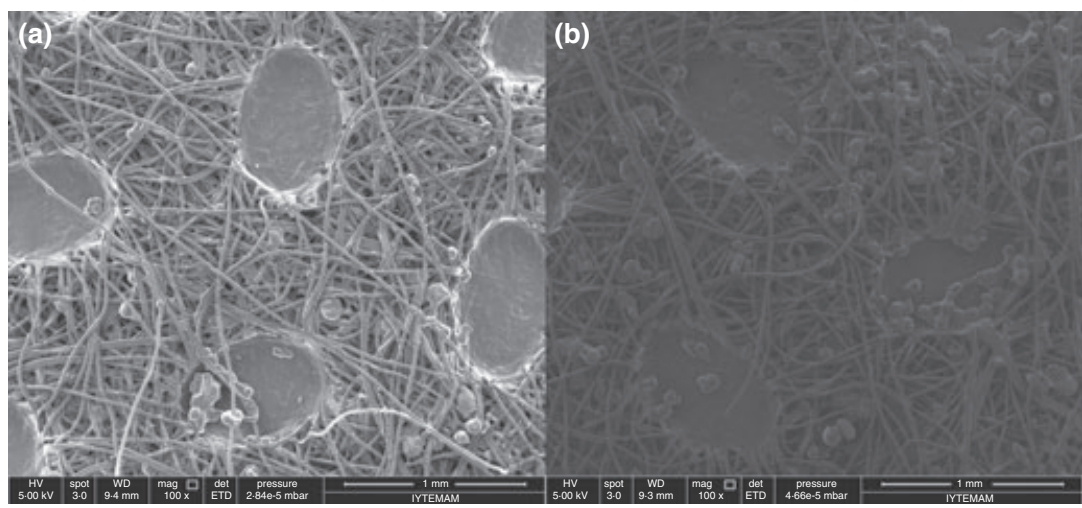

Figure 4 Difference between dry fabrics passed through baths including different amount of microcapsules: (a) fabric passed through bath including $20 \mathrm{~g} \mathrm{I}^{-1}$ microcapsule, (b) fabric passed through bath including $30 \mathrm{~g} \mathrm{I}^{-1}$ microcapsule. 
antimicrobial activity, ORPSO has a considerable antimicrobial activity against test micro-organisms with antibiotic resistance. ORPSO can be readily encapsulated by using complex coacervation to produce microcapsules. It has been possible to obtain functional textiles by applying ORPSO-loaded microcapsules to nonwoven fabrics.

\section{Materials and methods}

GE (from porcine skin, type A) and GA (from the acacia tree) were purchased from Sigma-Aldrich (Munich, Germany) and used as wall materials. Red pepper (Capsicum annuum) seed was a gift of Memişoğlu Spices Co. (Kahramanmaras, Turkey). RPSO was obtained using a cold press (KYP20D) Köprülü Machine Co. (Izmir, Turkey). RPSO was processed and ozonated in the Natural Products

Table 3 Agar well antimicrobial test results on microcapsules containing ozonated red pepper seed oil (ORPSO)

\begin{tabular}{llll}
\hline & \multicolumn{3}{l}{ Inhibition zone $(\mathrm{mm})^{\mathrm{a}}$} \\
\cline { 2 - 4 } & $\begin{array}{l}\text { Microcapsules } \\
\text { with ORPSO }\end{array}$ & $\begin{array}{l}(10 \mu \mathrm{g} \text { per } \\
\text { disc })\end{array}$ & $\begin{array}{l}\text { Nystatin } \\
(100 \mathrm{U} \text { per } \\
\text { disc })\end{array}$ \\
\hline $\begin{array}{c}\text { Microorganisms } \\
\begin{array}{c}\text { Escherichia coli } \\
\text { O157H7 }\end{array}\end{array}$ & 21.50 & 20.0 & $\mathrm{Nt}$ \\
$\begin{array}{c}\text { Pseudomonas } \\
\text { aeruginosa }\end{array}$ & 19.50 & 25.0 & $\mathrm{Nt}$ \\
$\begin{array}{c}\text { Methicillin-resistant } \\
\text { Staphylococcus } \\
\text { aureus }\end{array}$ & 22.50 & 23.0 & $\mathrm{Nt}$ \\
$\begin{array}{c}\text { Vancomycin-resistant } \\
\text { Enterococcus } \\
\text { faecium }\end{array}$ & 18.50 & 17.0 & $\mathrm{Nt}$ \\
\begin{tabular}{c} 
Candida albicans \\
\hline
\end{tabular} & 17.0 & $\mathrm{Nt}$ & 18.0 \\
\hline
\end{tabular}

$\mathrm{Nt}$, not tested.

${ }^{a}$ The values are the mean of three experiments. The zones of inhibition include the $6 \mathrm{~mm}$ diameter of the wells.
Research Development Unit (NPRDU/DUAG Ltd Co.) (Izmir Technology Development Zone, Izmir, Turkey). Tween $^{\circledR} 20 \quad\left(\mathrm{C}_{58} \mathrm{H}_{114} \mathrm{O}_{26}\right)$, sodium hydroxide $(\mathrm{NaOH})$, hydrochloric acid $(37 \%$, purity $\mathrm{HCl})$ and 2-propanol were purchased from Sigma-Aldrich. Polypropylene SMS (spunbond-meltblown) $\quad 100 \%$ nonwoven fabric weighing, $40 \mathrm{~g} \mathrm{~m}^{-2}$, was provided by Kisbu Textile (Izmir, Turkey). Deionized water was used in all the experiments.

\section{Characterization of RPSO and RPSO}

Gas chromatography-mass spectrometry analysis. A Hewlett-Packard 5890 including FID and HP innowax capillary column $(60 \mathrm{~m} \times 0.32 \mathrm{~mm}$ i.d.; $0.25 \mu \mathrm{m})$ combined with a mass spectrometer was used in the GC-MS analyses. The injector was set at $240^{\circ} \mathrm{C}$ with a splitting ratio of 1 : 50. Samples were diluted with $n$-hexane (40/100) prior to analysis. Helium was used as the carrier gas at $35 \mathrm{ml} \mathrm{min}{ }^{-1}$. The column temperature was maintained at $50^{\circ} \mathrm{C}$ for the first $5 \mathrm{~min}$ and then raised to $260^{\circ} \mathrm{C}$ at a rate of $5^{\circ} \mathrm{C}$ per minute, and then kept at $260^{\circ} \mathrm{C}$ for 5 min. The GC-MS analyses were performed at Arge Far (Ege University, Izmir, Turkey).

FTIR spectroscopy. The FTIR spectra of RPSO and ORPSO samples on $\mathrm{KBr}$ discs were recorded using an FT-IR spectrophotometer (Digilab FTS $3000 \mathrm{Mx}$, Randolph, MA, USA). A regular scanning range of $400-4000 \mathrm{~cm}^{-1}$ was used at a spectral resolution of $4 \mathrm{~cm}^{-1}$.

\section{Preparation of microcapsules}

Microcapsules containing ORPSO were prepared by a complex coacervation method according to a modified method published by Jouzel et al. (2003). Solutions of $2 \%$ (w/v) GE and GA were prepared. Four grams of polymer were dispersed into $200 \mathrm{ml}$ of deionized water at room

Table 4 The efficacy of bio-active fabrics functionalized by impregnation with ozonated red pepper seed oil (ORPSO) containing microcapsules against three selected micro-organisms

\begin{tabular}{|c|c|c|c|c|c|c|c|c|c|c|}
\hline \multirow[b]{3}{*}{ Test Organisms } & \multicolumn{2}{|l|}{ IMC } & \multicolumn{4}{|c|}{ 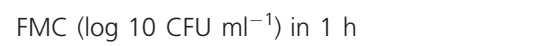 } & \multicolumn{4}{|c|}{ 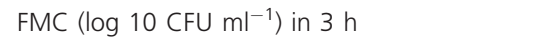 } \\
\hline & \multirow[b]{2}{*}{ Mean CFU ml-1 } & \multirow[b]{2}{*}{$\begin{array}{l}\log 10 \\
\text { CFU } \mathrm{ml}^{-1}\end{array}$} & \multicolumn{2}{|l|}{ C } & \multirow[b]{2}{*}{ BAF1 } & \multirow[b]{2}{*}{ BAF2 } & \multicolumn{2}{|l|}{ C } & \multirow[b]{2}{*}{ BAF1 } & \multirow[b]{2}{*}{ BAF2 } \\
\hline & & & Mean CFU $\mathrm{ml}^{-1}$ & $\begin{array}{l}\text { Log } 10 \\
\text { CFU ml }\end{array}$ & & & Mean CFU ml ${ }^{-1}$ & $\begin{array}{l}\text { Log } 10 \\
\text { CFU ml }\end{array}$ & & \\
\hline Escherichia coli & $1 \cdot 0 \cdot 106 \pm 2 \cdot 1 \cdot 104$ & $6 \cdot 0$ & $2 \cdot 0 \cdot 105 \pm 5 \cdot 2 \cdot 103$ & $5 \cdot 3$ & 0 & 0 & $5 \cdot 4 \cdot 104 \pm 1 \cdot 5 \cdot 103$ & $4 \cdot 7$ & 0 & 0 \\
\hline $\begin{array}{l}\text { Staphylococcus } \\
\text { aureus }\end{array}$ & $3 \cdot 5 \cdot 106 \pm 7 \cdot 3 \cdot 104$ & $6 \cdot 5$ & $2 \cdot 6 \cdot 105 \pm 8 \cdot 0 \cdot 103$ & $5 \cdot 4$ & 0 & 0 & $6 \cdot 4 \cdot 104 \pm 1 \cdot 4 \cdot 103$ & $4 \cdot 8$ & 0 & 0 \\
\hline $\begin{array}{l}\text { Candida } \\
\text { albicans }\end{array}$ & $4 \cdot 0 \cdot 106 \pm 7 \cdot 9104$ & $6 \cdot 6$ & $4 \cdot 2 \cdot 105 \pm 1 \cdot 4 \cdot 104$ & $5 \cdot 62$ & 0 & 0 & $6 \cdot 7 \cdot 104 \pm 3 \cdot 1 \cdot 103$ & $4 \cdot 8$ & 0 & 0 \\
\hline
\end{tabular}

CFU, colony forming units; C, control fabric; BAF1, bioactive fabric impregnated with $20 \%(\mathrm{w} / \mathrm{w})$ bioactive microcapsules; BAF2, bioactive fabric impregnated with $30 \%(\mathrm{w} / \mathrm{w})$ bioactive microcapsules; IMC, initial microbial counts; FMC, final microbial counts. 
temperature $\left(\sim 25^{\circ} \mathrm{C}\right)$ for $30 \mathrm{~min}$. The temperature of the aqueous solutions was increased to $40^{\circ} \mathrm{C}$ to dissolve the polymer, and the $\mathrm{pH}$ of the solutions was adjusted to $7 \cdot 0$ by adding $3 \mathrm{~mol} \mathrm{l}^{-1} \mathrm{NaOH}$. The GE solution was then added to a three-neck flask equipped with a mechanical stirrer. Different amounts of ORPSO (10 or $20 \mathrm{ml}$ ) were emulsified in GE solution by stirring at a speed of $350 \mathrm{rev}$ $\min ^{-1}$ at $40^{\circ} \mathrm{C}$. Different amounts of Tween ${ }^{\circledR} 20$ (1.6 or $3.2 \mathrm{ml}$ ), as a surfactant were added to the three- neck flask and the emulsion was stirred at $350 \mathrm{rev} \mathrm{min}^{-1}$ at $40^{\circ} \mathrm{C}$ for $30 \mathrm{~min}$ to form a stable oil-in-water emulsion. GA solution was added to the emulsion drop-wise and it was stirred again at $350 \mathrm{rev} \mathrm{min}^{-1}$ for $15 \mathrm{~min}$. The $\mathrm{pH}$ of the emulsion was adjusted to 4.0 with $1 \mathrm{~mol} \mathrm{l}^{-1} \mathrm{HCl}$ solution to stabilize the polymers. The coacervation was allowed to continue by stirring at $350 \mathrm{rev} \mathrm{min}^{-1}$ for $90 \mathrm{~min}$. At the end of the coacervation, the heater was switched off and $600 \mathrm{ml}$ of cold, deionized water was added to the coacervate to reduce the temperature of the coacervate to room temperature and also prevent agglomeration. The temperature of the coacervate was then reduced to $5-10^{\circ} \mathrm{C}$ with an ice bath. Consequently, GE and GA covered the solidified oil droplets and formed microcapsules. The system was stirred continuously at $350 \mathrm{rev} \min ^{-1}$ for $2 \mathrm{~h}$. After $2 \mathrm{~h}$ of hardening, microcapsules in the aqueous phase were transferred to a refrigerator overnight. Finally, the microcapsules were collected, rinsed with 2-propanol, filtered and dried at room temperature.

In the present study, the amount of oil ( $\mathrm{ml})$ and amount of surfactant $(\mathrm{ml})$ were chosen as experimental parameters in the preparation of the microcapsules. All other parameters were kept constant. For this purpose, four different treatments were prepared. The amounts of oil and surfactant used were varied from: 10 and $1 \cdot 6$, to 10 and $3 \cdot 2$, to 20 and $1 \cdot 6$, to 20 and $3 \cdot 2 \mathrm{ml}$ for treatments 1-4 respectively. All treatments were carried out in duplicate.

\section{Morphology of microcapsules}

The structure, shape and formation of microcapsules were observed using an optical microscope (Bresser ${ }^{\circledR}$ LCD Micro, Rhede, Germany) connected to a digital camera.

\section{Determination of micro-encapsulation yield}

The micro-encapsulation yield of ORPSO was determined by the following equation:

$$
\text { Micro-encapsulation yield }(\%)=\left(W_{1} / W_{2}\right) \times 100
$$

$W_{1}$ : weight of the microcapsules obtained

$W_{2}$ : initial weight of the materials used (combined weight of core and wall materials).

\section{Determination of particle size}

Images of microcapsules obtained by optical microscopy at the rinsing step of the micro-encapsulation process were used to measure the size of the microcapsules. Sizes of the microcapsules were measured using IMAGE J software (NIH, Bethesda, MD, USA) as pixels and transformed to microns using a scale. Seventy measurements were taken for each treatment and mean particle size was obtained from values of diameter of 70 different microcapsules. Particle-size distribution was determined by SPSS 15.0 statistical analysis software.

\section{Determination of oil loading}

Oil loading was determined using a centrifuge (Hettich, Tuttlingen, Germany) and UV-VIS spectrophotometer (Thermo Multiskan Spectrum, Barrington, IL, USA) with the following method. First, five different specific amounts of the oil were dissolved in $750 \mu \mathrm{l}$ of 2-propanol and a calibration curve was established with UV-VIS spectrophotometer at $275 \mathrm{~nm}$. Then, $0.05 \mathrm{~g}$ of microcapsules were dispersed in $750 \mu \mathrm{l}$ of 2-propanol.

Microcapsules in 2-propanol were shaken in a centrifuge to release the encapsulated oil completely. The concentration of the oil dissolved in 2-propanol was obtained by a UV-VIS spectrophotometer at $275 \mathrm{~nm}$. All determinations were carried out in triplicate and mean values were calculated.

\section{Determination of oil release with mechanical rupture}

The oil in microcapsules impregnated onto the fabric can be released by mechanical rupture of the capsule wall. For this reason, oil release was determined with the BioSpec mini bead-beater (Bartlesville, OK, USA). Microcapsules in 2-propanol were shaken with a BioSpec mini bead-beater to release the encapsulated oil. A UV-VIS spectrophotometer was also used to determine the oil release (\%) just as in the case of the oil loading determination method. All determinations were carried out in triplicate and mean values were calculated.

\section{Application of microcapsules to nonwoven fabric}

Microcapsules prepared at the optimum conditions were applied to $100 \%$ poly propylene nonwoven fabric using a laboratory type foulard (Ernst Benz 8153, Rümlang, Switzerland) in the finishing process of textile fabrication. Different amounts of microcapsules with ORPSO (20 or $30 \mathrm{mg} \mathrm{ml}^{-1}$ ) were suspended in a $500 \mathrm{ml}$ bath containing only deionized water. The following equation was used to determine the pick-up ratio of the fabric. 
Pick-up ratio $(\%)=($ mass of bath solution taken

by the fabric/mass of dry fabric) $\times 100$

The foulard with two rollers was used at $7 \mathrm{~m} \mathrm{~min}^{-1}$ of working speed and 6 bar of pressure of rollers and the pick-up ratio of the fabric was fixed at $150 \%$. A fabric of $20 \mathrm{~cm}$ width and $60 \mathrm{~cm}$ length was passed through the bath and subsequently through squeeze rollers. The padded fabrics were dried for 1 day at room temperature $\left(\sim 25^{\circ} \mathrm{C}\right)$.

Analysis of microcapsules impregnated on the padded fabric

Microcapsules in the padded fabric and their structures were also observed by scanning electron microscopy [SEM; Philips (FEI) XL30-SFEG, Eindhoven, the Netherlands].

\section{Antimicrobial activities of RPSO, ORPSO and micro capsules with ORPSO}

The antimicrobial activity of the RPSO was determined by means of the disc diffusion method described by the National Committee for Clinical Laboratory Standards (NCCLS 2003). Several antibiotic-resistant test strains were used for experiments: E. coli O157H7, Ps. aeruginosa ATCC 27853, methicillin-resistant Staph. aureus RSKK 95047, vancomycin-resistant Enterococcus faecium DSMZ 13590 and C. albicans DSMZ 5817. All tests were performed in Mueller-Hinton agar (MHA; Oxoid, Basingstoke, UK) and Sabouraud Dextrose agar (SDA; Difco, Detroit, MI, USA) for bacteria and $C$. albicans respectively. For the disc diffusion assay, fifteen microlitres of ozone- treated and untreated RPSO samples were injected into sterile discs of $6 \mathrm{~mm}$ in diameter (Murray et al. 1995). Gentamycin $(10 \mu \mathrm{g})$ and nystatin $(100 \mathrm{U})$ were used as positive reference standards to determine the sensitivity of the tested strains. All experiments were done in triplicate.

The antimicrobial activities of the microcapsules with ORPSO were tested using the agar well method (Bell and Grundy 1968). One hundred microlitres of suspension containing $10^{6} \mathrm{CFU} \mathrm{ml} \mathrm{m}^{-1}$ bacteria and $10^{5} \mathrm{CFU} \mathrm{ml} \mathrm{ml}^{-1}$ yeasts were spread onto sterile petri dishes containing MHA and SDA respectively. Six-mm wells were excised aseptically and filled with $50 \mathrm{mg}$ microcapsules containing ORPSO. The plates were kept at $4^{\circ} \mathrm{C}$ for $2 \mathrm{~h}$ and then incubated at $35^{\circ} \mathrm{C}$ for $24 \mathrm{~h}$ for bacteria and $48 \mathrm{~h}$ for yeasts. The results were recorded by measuring the zones of growth inhibition surrounding the wells. All experiments were done in triplicate.

Antimicrobial activity of the nonwoven fabrics. Three selected antibiotic-resistant test microorganisms (methicillin-resistant S. aureus RSSK 232, E. coli O157:H7 and C. albicans DSMZ 5817) were used to assess the antimicrobial effectiveness of the fabrics. The modified method of Mariscal et al. (2010), with modifications was used. Briefly, bacteria were grown overnight in MuellerHinton broth (MHB; Oxoid) and C. albicans was grown in Sabouraud Dextrose Broth (SDB; Difco) at $37^{\circ} \mathrm{C}$ and collected by centrifugation. These were then rinsed twice in PBS buffer and resuspended to obtain $10^{6} \mathrm{CFU} \mathrm{ml^{-1 }}$ viable micro-organisms detected by plating on MHA and SDA for determination of IMC.

The nonwoven test fabric was used as a control, and nonwoven fabrics loaded with microcapsules containing ORPSO were used as bio-active fabrics. All test materials were sterilized with ethylene oxide before the assay by using an Ethylene Oxide sterilization system (Axis, Izmir, Turkey). Pieces $\left(5 \mathrm{~cm}^{2}\right)$ of the sterilized fabrics were placed in sterile plastic petri dishes and inoculated with $100 \mu \mathrm{l}$ of the microbial suspension. The plates were kept at room temperature in a $60 \%$ humidified incubator for 1 and $3 \mathrm{~h}$ respectively. The fabrics were then removed using sterile pincers, and immersed in a sterile test tube containing $10 \mathrm{ml}$ of $0 \cdot 2 \%$ Tween 80 in PBS buffer. The tubes were subjected to vigorous vortexing for $3 \mathrm{~min}$. One hundred- $\mu$ l aliquots from each tube were serially diluted in $900 \mu \mathrm{l}$ of sterile saline solution $(0 \cdot 85 \% \mathrm{w} / \mathrm{v}$ of $\mathrm{NaCl})$ and then plated on agar media MHA and SDA. After incubating for $24 \mathrm{~h}$ at $37^{\circ} \mathrm{C}$, FMC were calculated. The CFU data were analyzed using Tukey's and LSD tests in ANOvA (Michelson and Schofield 2002). A $P$-value $<0.05$ was considered significant. All tests were done in triplicate.

\section{Statistical analysis}

Experimental results were analyzed by SPSS 15.0 statistical analysis software for statistical analysis of means, standard deviations and significant differences. Effects of amount of oil, amount of surfactant parameters and their interaction were analyzed at a $95 \%$ confidence interval.

\section{Acknowledgements}

The authors are grateful for financial support from the Natural Products Research Development Unit (NPRDU/ DUAG-011) located in Izmir Technology Development Zone. We express our thanks to Akçay Olcay for helping to perform some of the experiments as a part of his Project, which was chosen the second best high school project in the nation by the Turkish Scientific Research Council.

\section{References}

Agaoglu, S., Dostbil, N. and Alemdar, S. (2007) Antimicrobial activity of some spices used in the meat industry. $B V I$ Pulawy 51, 53-57. 
Aguilera, A. and Gómez-González, B. (2008) Genome instability: a mechanistic view of its causes and consequences. Nat Rev Genet 9, 204-217.

Augustin, M.A. and Hemar, Y. (2009) Nano- and microstructured assemblies for encapsulation of food ingredients. Chem Soc Rev 38, 902-912.

Badulescu, R., Vivod, V., Jausovec, D. and Voncina, B. (2008) Grafting of ethylcellulose microcapsules onto cotton fibers. Carbohydr Polym 71, 85-91.

Bansode, S.S., Banarjee, S.K., Gaikwad, D.D., Jadhav, S.L. and Thorat, R.M. (2010) Microencapculation: a review. Int J Pharm Sci Rev Res 1, 38-43.

Baumann, H., Bühler, M., Fochem, H., Hirsinger, F., Zoebelin, H. and Falbe, J. (1988) Natural fats and oils-renewable raw materials for the chemical industry. Angew Chem Int Ed Engl 27, 41-62.

Bell, S.C. and Grundy, W.E. (1968) Preparation of agar wells for antibiotic assay. Microbiology 16, 1611-1612.

Benita, S. (1996) Microencapsulation: Methods and Industrial Applications., Inc. pp. 640. New York, NY, USA: Marcel Dekker.

Bonin, L.E. (2008) Durable and reusable antimicrobial textiles. pp. 42. Master of Science Thesis, Louisiana State University Agricultural and Mechanical College, USA.

Bukar, N.V., Krasnobaeva, S.Y., Ilyushenko, E.V., Avramenko, G.V. and Kienskaya, K.I. (2008) Methods for microencapsulation of N-benzylmorpholine. Russ J Appl Chem 81, 276-280.

Careaga, M., Fernández, E., Dorantes, L., Mota, L., Jaramillo, M. and Hernández-Sánchez, H. (2003) Antibacterial activity of capsicum extract against Salmonella typhimurium and Psedomonas aeruginosa inoculated in raw beef meat. Int J Food 83, 331-5.

Chang, C-P., Leung, T-K., Lin, S-M. and Hsu, C-C. (2006) Release properties on gelatin - gum arabic microcapsules containing camphor oil with added polystyrene. Colloids Surf B Biointerfaces 50, 136-140.

Cosco, S., Ambrogi, V., Musto, P. and Carfagna, C. (2007) Properties of poly (urea- formaldheyde) microcapsules containing an epoxy resin. J Appl Polym Sci 105, 14001411.

Cronheim, G. (1947) Organic ozonides as chemotherapeutic agents. I. Chemical studies. J Am Pharm Assoc 36, 274278.

Daniels, R. and Mittermaier, E.M. (1995) Influence of pH adjustment on microcapsules obtained from complex coacervation of gelatin and acacia. J Microencapsul 12, 591 -599 .

Deveci, S. and Basal, G. (2009) Preparation of PCM microcapsules by complex coacervation of silk fibroin and chitosan. Colloid Polym Sci 287, 1455-1467.

Duarte, C., Mold, O.M., Gouveia, M., Costa, A., Leit, S., Bernardo, A. and Gil, M. (2004) Supercritical fluid extraction of red pepper (Capsium frutescens L.). J Supercrit Fluids 30, 155-161.
El-Adawy, T.A. and Taha, K.M. (2001a) Characteristics and composition of different seed oils and flours. Food Chem 74, 47-54.

El-Adawy, T.A. and Taha, K.M. (2001b) Characteristics and composition of watermelon, pumpkin, and paprika seed oils and flours. J Agric Food Chem 49, 1253-1259.

El-Zawahry, M.M., El-Shami, S. and El-Mallah, M.H. (2007) Optimizing a wool dyeing process with reactive dye by liposome microencapsulation. Dyes Pigm 74, 684.

FAO (2008) Food Agriculture Organization of the United Nations Statistical Databases. http://faostat.fao.org (accessed January 2008).

Fıratlıgil-Durmuş, E. and Evranuz, O. (2010) Solubility and emulsifying properties of red pepper seed flour and protein. ITÜ Dergisi/D Mühendislik 4, 33-44.

Giraud, S., Bourbigot, S., Rochery, M., Vroman, I., Tighzert, L., Delobel, R. and Poutch, F. (2005) Flame retarded polyurea with microencapsulated ammonium phosphate for textile coating. Polym Degrad Stab 88, 106-113.

Green, B.K. and Schleicher, L. (1957) Oil-Containing Microscopic Capsules and Method of Making Them. US Patent Application 2800 457, The National Cash Register.

Hammer, K.A., Carson, C.F. and Riley, T.V. (1999) Antimicrobial activity of essential oils and other plants extract. J Appl Microbiol 86, 985-990.

Harrington, J.C. and Morris, E.R. (2009) Conformational ordering and gelation of gelatin in mixtures with soluble polysaccharides. Food Hydrocol 23, 327-336.

Harrison, K.A. and Murphy, R.C. (1996) Direct mass spectrometric analysis of analysis of ozonides: application to unsaturated glycerophosphocholine lipids. Anal Chem 68, 3224-3230.

Hill, K. (2007) Industrial development and application of biobased oleochemicals. Pure Appl Chem 79, 1999-2011.

Holmes, J. (2008) Ozonated Liquids in Dental Practice - A Review. Part 4: The Chemistry of Ozone in Plant Oils. http://www.the-o-zone.cc/HTMLOzoneF/o3liquids/o3lpt05. pdf.

Hong, K. and Park, S. (1999) Melamine resin microcapsules containing fragrant oil: synthesis and characterization. Mater Chem Phys 58, 128-131.

Huang, Y-I., Cheng, Y-H., Yu, C-C., Tsai, T-R. and Cham, TM. (2007) Microencapsulation of extract containing shikonin using gelatin - acacia coacervation method: a foraldehyde-free approach. Colloids Surf B Biointerfaces 58, 290.

John, J., Bhattacharya, M. and Raynor, P.C. (2004) Emulsions containing vegetable oils for cutting fluid application. Colloids Surf A Physicochem Eng Asp 237, 141-150.

Jouzel, B., Pennarun, A-L., Prost, C., Renard, D., Poncelet, D. and Demaimay, M. (2003) Encapsulation of a lipid precursor, the eicosapentaenoic acid, to study the development of the Crassostrea gigas oyster flavours. J Microencapsul 20, 35-46. 
Jung, M.Y., Bock, J.Y., Baik, S.O., Lee, J.H. and Lee, T.K. (1999) Effects of roasting on pyrazine contents and oxidative stability of red pepper seed oil prior to its extraction. J Agric Food Chem 47, 1700-1704.

Köekritz, A. and Martin, A. (2011) Synthesis of azelaic acid from vegetable oil- based feedstocks. Eur J Lipid Sci Technol 113, 83-91.

Leclercq, S. (2008) Stability and release of model aroma compounds. PhD thesis. Faculty of the Graduate School of the University of Minnesota, USA.

Leclercq, S., Harlander, K.R. and Reineccius, G.A. (2009) Formation and characterization of microcapsules by complex coacervation with liquid and solid aroma cores. Flavor Fragrance J 24, 17-24.

Leelajariyakul, S., Noguchi, H. and Kiatkamjornwong, S. (2008) Surface-modified and micro-encapsulated pigmented inks for ink jet printing on textile fabrics. Prog Org Coat 62, 145-161.

Leeming, J.P., Holland, K.T. and Bojar, R.A. (1986) The in vitro antimicrobial effect of azelaic acid. Br J Dermatol 115, 551-556.

Li, G., Song, C., You, J., Sun, Z., Xia, L. and Suo, Y. (2011) Optimisation of red pepper seed oil extraction using supercritical $\mathrm{CO}_{2}$ and analysis of the composition by reversed-phase HPLC-FLD-MS/MS. Int J Food Sci Technol 46, 44-51.

Ma, Z-H., Yu, D-G., Brandford-White, C.J., Nie, H-L., Fan, Z-X. and Zhu, L-M. (2009) Microencapsulation of tamoxifen: application to cotton fabric. Colloids Surf $B$ Biointerfaces 69, 85-90.

Mariscal, A., Lopez-Gigosos, R.M., Carnero-Varo, M. and Fernandez-Crehuet, J. (2010) Antimicrobial effect of medical textiles containing bioactive fibres. Eur J Clin Microbiol Infect Dis 30, 227-232.

Maritza, D., Hemandez, F.R., Martinez, G., Vidal, G., Gomez, M., Fermandez, H. and Garces, R. (2006) Comparative study of ozonized olive oil and ozonized sunflower oil. J Braz Chem Soc 17, 403-407.

Mayya, K.S., Bhattacharyya, A. and Argillier, J-F. (2003) Micro-encapsulation by complex coacervation: influence of surfactant. Polym Int 52, 644-647.

Michelson, S. and Schofield, T. (2002) The Biostatistics Cookbook. pp. 170. New York, USA: Kluywer Academic Publishers.

Mirabal, J.M., Menendez Cepero, S.A., Diaz Rubi, V.F., Garcia, LAF., Ledea Lozano, O.E., Diaz Gomez, M.F. and Lezcano Lastre, I.D. (2003) Method for obtaining ozonized oils and vegetable fats and use of said products for pharmaceutical and cosmetic purposes. WO 03/085072 A1.

Moise, T. and Rudich, Y. (2002) Reactive uptake of ozone by aerosol-associated unsaturated fatty acids: kinetics mechanis and products. J Chem Phys 106, 6469-6476.

Murray, P.R., Baron, E.F., Pfaller, M.A., Tenover, F.C. and Yolke, R.H. (1995) Manual of Clinical Microbiology, 6th edn. Washington, DC: ASM.
National Committee for Clinical Laboratory Standards (NCCLS) (2003) Method for Antifungal Disk Diffusion Susceptibility Testing of Yeasts; Proposed Guideline. NCCLS document M44-P (ISBN 1-56238-488-0). Wayne, PA: NCCLS.

Nelson, G. (2002) Application of microencapsulation in textiles. Int J Pharm 242, 55-62.

N'Guessan, R., Knols, B.G.J., Pennetier, C. and Rowland, M. (2008) DEET microencapsulation: a slow-release formulation enhancing the residual efficacy of bed nets against malaria vectors. Trans $R$ Soc Trop Med Hyg 102, 259-262.

Onder, E., Sarier, N. and Cimen, E. (2008) Encapsulation of phase change materials by complex coacervation to improve thermal performance of woven fabrics. Thermochim Acta 467, 63-72.

Ovez, B. and Yuksel, M. (2002) Slow release of parfumes from crosslinked microcapsules. Ekoloji Issue 10, 26-29.

Porro, M.N. (1987) Azelaic acid. J Am Acad Dermatol 17, 1033 -1041 .

Prata, A.S., Menut, C., Leydet, A., Trigo, J.R. and Grosso, C.R. F. (2008) Encapsulation and release of a fluorescent probe, khusimyl dansylate, obtained from vetiver oil by complex coacervation. Flavour Fragr J 23, 7-15.

Qingwen, S., Yi, L., Jianwei, X., Hu, J.Y. and Yuen, M. (2007) Thermal stability of composite phase change material microcapsules incorporated with silver nano- particles. Polymer 48, 3317-3323.

Ramachandran, T., Rajendrakumar, K. and Rajendran, R. (2004) Antimicrobial textiles - an overview. Inst Eng (Ind) J-TX 84, 42-47.

Rodrigues, S.N., Marins, I.M., Fernandes, I.P., Gomes, P.B., Mata, V.G., Barreiro, M.F. and Rodrigues, A.E. (2009) Scentfashion ${ }^{\circledR}$ : microencapsulated perfumes for textile applications. Chem Eng J 149, 463-472.

Sahin, N., Kula, I. and Erdoğan, Y. (2006) Investigation of Antimicrobial Activities of Nonanoic Acid Derivaties. Fresen Environ Bull 2, 141-143.

Sim, K.H. and Sil, H.Y. (2008) Antioxidant activities of red pepper (Capsium annuum) pericarp and seed extracts. Int J Food Sci Technol 43, 1813-1823.

Song, W-Y., Ku, K-H. and Choi, J-H. (2010) Effect of ethanol extracts from red pepper seeds on antioxidative defense system and oxidative stress in rats fed high-fat highcholesterol diet. Nutr Res Pract 4, 11-15.

Soriano, U.N., Veronica, J., Migo, P. and Matsumura, M. (2003a) Ozonation of sunflower oil: spectroscopic monitoring of the degree of unsaturation. JAOCS $\mathbf{8 0}, 726-$ 730.

Soriano, N.U. Jr, Migo, V.P. and Matsumura, M. (2003b) Functional group analysis during ozonization of sunflower oil methyl esters by FT-IR and NMR. Chem Phys Lipids 126, 133-140.

Tavaria, F.K., Soares, J.C., Reis, I.L., Paulo, M.H., Malcata, F.X. and Pintado, M.E. (2012) Chitosan: antimicrobial action 
upon staphylococci after impregnation onto cotton fabric. J Appl Microbiol 112, 1034-1041.

Torres, J.M., Garcia-Chaves, A. and Ramirez-Chaves, E. (1999) Antimicrobial properties of alkamides present in flavouring plants traditionally used in Mesoamerica: affinin and capsaicin. J Ethnopharmacol 64, 241-248.

Tran, P., Gravier, D. and Narayan, R. (2005) Ozonemediated polyol synthesis from soybean oil. JACQS 82, 653-659.

Vahapzadeh, F., Zivdar, M. and Najafi, A. (2004) Microencapsulation of orange oil by complex coacervation and its release behavior. IJE T B: Appl 17, 333-342.

Vlachos, N., Skopelitis, Y., Psaroudaki, M., Konstantinidou, V., Chatzilazarou, A. and Tegou, E. (2006) Applications of
Fourier transform- infrared spectroscopy to edible oils. Anal Chim Acta 573-574, 459-465.

Xing, F., Cheng, G., Yang, B. and Ma, L. (2004) Microencapsulation of capsaicin by complex coacervation of gelatin, acacia and tannins. J Appl Polym Sci 91, 2669-2675.

Yeo, Y., Bellas, E., Firestone, W., Langer, R. and Kohane, D.S. (2005) Complex coacervates for thermally sensitive controlled release of flavor compounds. J Agric Food Chem 53, 7518-7525.

Zanardi, I., Travagli, V., Gabbrielli, A., Chiasserini, L. and Bocci, V. (2008) Physico- chemical characterization of sesame oil derivates. Lipids 43, 877-886. 